OPEN ACCESS

Edited by:

Alfonso Jose Lag Brotons, Lancaster University, United Kingdom

Reviewed by:

John Senko,

University of Akron, United States

Susan Childers,

Colby College, United States

*Correspondence:

Jonathan R. Lloyd

Jon.Lloyd@manchester.ac.uk

Specialty section:

This article was submitted to

Microbiological Chemistry and

Geomicrobiology,

a section of the journal

Frontiers in Environmental Science

Received: 08 June 2018

Accepted: 10 October 2018

Published: 05 November 2018

Citation:

Joshi N, Filip J, Coker VS, Sadhukhan J, Safarik I, Bagshaw H

and Lloyd JR (2018) Microbial

Reduction of Natural Fe(III) Minerals;

Toward the Sustainable Production of

Functional Magnetic Nanoparticles.

Front. Environ. Sci. 6:127

doi: 10.3389/fenvs.2018.00127

\section{Microbial Reduction of Natural Fe(III) Minerals; Toward the Sustainable Production of Functional Magnetic Nanoparticles}

\author{
Nimisha Joshi ${ }^{1}$, Jan Filip ${ }^{2}$, Victoria S. Coker ${ }^{1}$, Jhuma Sadhukhan ${ }^{3}$, Ivo Safarik ${ }^{2,4}$, \\ Heath Bagshaw ${ }^{1}$ and Jonathan R. Lloyd ${ }^{1 *}$ \\ ${ }^{1}$ Williamson Research Centre for Molecular Environmental Science and School of Earth \& Environmental Sciences, University \\ of Manchester, Manchester, United Kingdom, ${ }^{2}$ Regional Centre of Advanced Technologies and Materials, Palacký University, \\ Olomouc, Czechia, ${ }^{3}$ Centre for Environment and Sustainability, University of Surrey, Surrey, United Kingdom, ${ }^{4}$ Department of \\ Nanobiotechnology, Institute of Soil Biology, Biology Centre CAS, Ceské Budějovice, Czechia
}

The microbial synthesis of biominerals offers a potentially sustainable green solution for the production of a wide range of industrially relevant functional nanomaterials. Metal-reducing bacteria are of particular relevance, as they can enzymatically reduce a wide spectrum of high oxidation state metals and metalloids, forming cell-templated nanomagnets, catalysts, remediation agents, and quantum dots. Although these bioprocesses have been shown to be both scalable and tunable (with respect to particle size, reactivity, magnetic properties, and light emitting properties), they have yet to be taken up by industry. Here, we show that naturally abundant Fe(III) minerals are appropriate raw materials for the production of magnetic Fe(II)-bearing nanoparticles by the subsurface bacterium Geobacter sulfurreducens, and these bionanomaterials have the potential for remediation applications-here confirmed by the efficient reduction of toxic, mobile $\mathrm{Cr}(\mathrm{VI})$ to less toxic and soluble $\mathrm{Cr}(\mathrm{III})$. Detailed molecular-scale characterization of the bioreduced nanominerals, alongside life cycle assessments, and life cycle costings, confirm the efficient production of highly reactive and magnetic nanomaterials from waste materials. This adds further weight to the adoption of microbial technologies for sustainable, functional nanomaterials in a circular economy.

Keywords: bionanominerals, remediation, revalorization, sustainability analysis, iron-oxides

\section{INTRODUCTION}

Metal-reducing bacteria can respire a broad range of high oxidation state metals and mineral phases, influencing their biogeochemical fate in environmental systems. Harnessing these microbial processes "ex situ" can also offer biosynthetic routes for the formation of metallic nanoparticles with commercial potential (Macaskie et al., 2010; Ingale and Chaudhari, 2013). Such biosynthetic routes have a potential advantage over alternative chemical synthesis pathways, as they minimize the use of harsh chemicals and operate at ambient temperatures. Biogenic nanoparticles are used for a range of applications including catalysis, healthcare treatments, magnetic technologies and remediation applications (Mandal et al., 2006; Byrne et al., 2011; Ingale and Chaudhari, 2013). Bionanomagnetite is one such nanoparticle that offers the potential to remediate a variety of metals, 
radionuclides, and organics (Zhang and Elliot, 2006; Laurent et al., 2008) with an added advantage of being magnetically recoverable (Majiewsky and Thierry, 2007). It is synthesized by using Fe(III)-respiring bacteria such as Geobacter sulfurreducens and Shewanella oneidensis, that mediate this process in the presence of acetate or lactate as electron donors and Fe(III) oxyhydroxide as the terminal electron acceptor (Lovley et al., 1987). This biosynthetic route is scalable and can be fine-tuned to optimize particle size (by controlling the biomass loading; Byrne et al., 2011), magnetic properties (e.g., by incorporation of dopants; Byrne et al., 2013) and, surface reactivity (e.g., by incorporating $\mathrm{Pd}$ on its surface to form a heterostructure with improved reactivity; Coker et al., 2010).

$\mathrm{Fe}(\mathrm{II})$ bearing nanomaterials, such as bionanomagnetite (BNM), can be used to remediate and stabilize a range of redoxactive toxic metals, e.g., $\mathrm{Cr}(\mathrm{VI})$ and $\mathrm{Tc}(\mathrm{VII})$ (Telling et al., 2009; Cutting et al., 2010; Watts et al., 2015) and, organics including nitrobenzene, azo dyes, and perchloroethylene (PCE) (Crean et al., 2012; Coker et al., 2014; Watts et al., 2016). Although bionanomagnetite can be synthesized from a range of ferric iron mineral phases (Cutting et al., 2012), existing laboratory-scale methods usually employ precursors made by using analytical grade salts of iron and strong alkali, which if used at scale, would impact on overall production costs and increase environmental impact. Indeed, there is abundant literature on biogenic nanomaterials and their remediation potential (Lloyd, 2003; Macaskie et al., 2010; Lloyd et al., 2011) however, with insufficient data on manufacturing costs incurred during scale up operations, these bionanomaterials have not been able to compete commercially with their chemically synthesized counterparts. However, Fe(III) minerals are naturally abundant and can also be sourced from waste processes and may, therefore, offer suitable raw materials for the cost-effective synthesis of biogenic nanomaterials.

Sustainability analysis using life cycle assessment (LCA) approaches can play a crucial role in facilitating the industrial uptake of bionanomaterials. LCA is a holistic tool used for evaluation of the environmental feasibility of a process in its entirety through appropriate life cycle stages. For this, it is essential to scrutinize current industrial practices from the LCA based sustainability perspectives and recommend a more circular economy approach, replacing unsustainable practices. Industrial processes currently used for "abiotic" magnetite synthesis can include mining, crushing, grinding, concentration steps, titrations, filtration, and pelletization. These unit operations consume heat, electricity and raw materials. A recent European study shows that the consumption of raw materials, heat, and, power, sourced from fossil resources, has a potential to cause global warming and resource depletion amongst many other environmental impacts (Sadhukhan et al., 2017). This is not a sustainable scenario and needs to be replaced by cost-effective and environmental-friendly resource recovery from waste (RRfW) systems. Additionally, life cycle costing (LCC), is also vital to underpin commercialization of novel nanomaterial biosynthesis routes, identifying the economic costs and benefits across a product lifecycle, considering the same system boundaries as in LCA.
Here, for the first time, we demonstrate the use of sustainable $\mathrm{Fe}$ (III)-rich minerals, procured from contrasting natural systems, as raw materials for the biosynthesis of magnetic $\mathrm{Fe}(\mathrm{II})$-nanoparticles for remediation applications. Two natural sources of $\mathrm{Fe}(\mathrm{III})-(1)$ iron-rich precipitate from mine tailings impoundments at Zlate Hory, Czech Republic (Filip et al., 2007) and (2) an Fe(III)oxide material accumulated by the $\mathrm{Fe}(\mathrm{II})$ Mn(II) oxidizing bacterium Leptothrix (Safarik et al., 2017), have been used as natural precursors. The reductive transformation of these materials by resting cells of G. sulfurreducens resulted in the biosynthesis of $\mathrm{Fe}$ (II)-rich nanoparticles, which proved highly efficient for the treatment of hexavalent chromium in batch studies. Building on initial LCA of bionanomagnetite production via the conversion of laboratory synthesized Fe(III) minerals (Sadhukhan et al., 2017), analysis of the use of naturallyoccurring $\mathrm{Fe}$ (III) feedstocks (in this study) suggest significant environmental and economic savings and confirm an important first step toward the sustainable revalorization of $\mathrm{Fe}$ (III)-rich waste materials for novel technologies, including the remediation of metals and organics.

\section{MATERIALS AND METHODS \\ Chemicals and Reagents}

All the chemicals were procured from Sigma Aldrich and Fluka chemicals and used without further purification.

\section{Characterization of Different Fe(III) Sources Used in the Study}

Two sources of Fe(III) mineral were used in this study. The first source was an iron oxyhydroxide precipitate, that was collected from the seepage water of mine tailings at Zlaté Hory mine district, Czech Republic (Filip et al., 2007) at two-time points. The first sampling was done in 2015 (labeled as ZH2015) and the second in the following year (labeled as ZH2016). The samples collected were treated differently; ZH2015 was air-dried and sieved before storage for 1 year while ZH2016 was not treated and used immediately. Drying and lyophilisation were done to determine if variables such as temperature, pressure and time influence the stability of mineral phase. Sampling at two different time points was done to determine the impact of seasonal variations on the mineral composition of both, the starting material and the end product. The other sample tested was an ochreous Fe(III)-rich material associated with sheaths of the Fe(II)-oxidizing bacterium Leptothrix (labeled as LEPTH). Leptothrix species form filamentous microtubular structure and accumulate Fe or Mn in them (Safarik et al., 2017). This sample was collected from an unnamed stream in Ceské Budějovice, Czech Republic ( $\left.48^{\circ} 58^{\prime} 22.57^{\prime \prime} \mathrm{N}, 14^{\circ} 27^{\prime} 39.93^{\prime \prime} \mathrm{E}\right)$ in 2016. After analysis for associated mineral phases, the samples (ZH2015, ZH2016 and LEPTH) were washed with deionised water and added to an anaerobic bioreduction assay, as described below. Two-line ferrihydrite was synthesized in the laboratory by alkaline hydrolysis of $\mathrm{FeCl}_{3}$ with $\mathrm{NaOH}$ as described previously (Byrne et al., 2011), and was used as a positive control in all bioreduction experiments as it has been shown to transform into 
bionanomagnetite (Cutting et al., 2009), with proven remediation potential for both heavy metals and organics.

\section{Bacterial Strain, Growth Medium, and Bioreduction Assay}

Dissimilatory microbial reduction of slurries of synthetic ferrihydrite or natural $\mathrm{Fe}$ (III) phases was achieved by using washed cells of G. sulfurreducens. The bacteria were grown in a freshwater medium (Lovley et al., 1987) with $25 \mathrm{mM}$ sodium acetate as the electron donor and $40 \mathrm{mM}$ sodium fumarate as the electron acceptor at $30^{\circ} \mathrm{C}$ under anaerobic conditions in the dark. The harvested cells (late exponential phase) were added to a buffer with $30 \mathrm{mM} \mathrm{NaHCO} 3$ and $20 \mathrm{mM}$ sodium acetate (electron donor; Lovley and Phillips, 1986), and synthetic ferrihydrite or natural $\mathrm{Fe}(\mathrm{III})$ phases $(30 \mathrm{mM}$ equivalent $\mathrm{Fe}$ ) as the sole electron acceptor, and incubated in an atmosphere of $\mathrm{N}_{2}: \mathrm{CO}_{2}(80: 20 \mathrm{vol} / \mathrm{vol})$. Ten micrometer of anthraquinone-2,6disulfonate (AQDS) was used as an electron shuttle to accelerate the extracellular reduction of the Fe(III) substrates. The samples were collected from the reaction vessel under $\mathrm{N}_{2}$, and microbial reduction of the substrates was monitored by measuring $\mathrm{Fe}$ (II) accumulation by a ferrozine assay (Stookey, 1970). The total bioavailable iron was also determined after complete reduction of the slurry sample after the addition of $6.2 \mathrm{M}$ hydroxylamine hydrochloride as described previously (Watts et al., 2014).

\section{Analytical Techniques}

The identification and characterization of iron-bearing phases in all samples was performed using a combination of X-ray powder diffraction and ${ }^{57} \mathrm{Fe}$ Mössbauer spectroscopy. The samples for ${ }^{57} \mathrm{Fe}$ Mössbauer spectroscopy were frozen before analysis to avoid oxidation of iron, or transformation of nanocrystalline phases during data collection (Filip et al., 2014). The samples were measured in transmission geometry (constant acceleration mode) with a ${ }^{57} \mathrm{Co}(\mathrm{Rh})$ radioactive source $(1.85 \mathrm{GBq})$ at a temperature of $200 \mathrm{~K}$. The values of the hyperfine parameters (e.g., isomer shifts) were calibrated against a metallic iron $(\alpha-$ $\mathrm{Fe}$ ) foil at room temperature. The spectra were folded and fitted by Lorentz functions using the CONFIT2000 software (Zak and Jiraskova, 2006).

$\mathrm{X}$-ray powder diffraction patterns were recorded at room temperature with a PANalytical EMPYREAN diffractometer in the Bragg-Brentano geometry, $\mathrm{Co} K_{a}$ radiation $(40 \mathrm{kV}, 30 \mathrm{~mA}$, $\lambda=0.1789 \mathrm{~nm}$ ), equipped with a PIXcel3D detector and programmable divergence and diffracted beam anti-scatter slits. The wet samples were spread on a zero-background singlecrystal Si slide and air-dried just before measurement. Data were collected in a continuous mode (with a step size of $0.017^{\circ}$ in a $2 \theta$ range from 10 to $90^{\circ}$ ) under ambient conditions. Phase identification was performed using PANalytical HighScore Plus software with PDF-4+ database. Inductively Coupled Plasma Atomic Emission Spectroscopy (ICP-AES) was performed on a Perkin Elmer Optima 5300 dual view instrument for total iron determination after extraction in concentrated $\mathrm{HCl}(11.6 \mathrm{M})$.

$\mathrm{X}$-ray magnetic circular dichroism (XMCD) analysis was also done to determine the magnetic properties of the bioreduced samples. X-ray absorption (XA) spectra were collected at the Fe
$L_{2,3}$ edges on beamline 4.0.2 at the Advanced Light Source (ALS), Berkeley, CA, using the eight-pole resistive magnet end station (Arenholz and Prestemon, 2005). Dry samples were prepared under anaerobic conditions, and the powders then mounted on the sample manipulator using carbon tape. They were stored under anoxic conditions before entering the end station that was maintained under ultra-high vacuum. XAS data were collected in total-electron yield (TEY) mode, and at each photon energy of the spectrum, a measurement was made for two opposite magnetization directions (set parallel and anti-parallel to the beam direction with a field strength of $0.6 \mathrm{~T}$ ). After normalization to the incident beam intensity, the XMCD was calculated as the difference between the two XAS spectra (Pattrick et al., 2002).

$\mathrm{Fe}$ (II) to $\mathrm{Fe}$ (III) ratio was obtained by fitting the experimental XMCD (a non-linear least-squares analysis) to the calculated spectra for each site. Fitting of the spectra was done by previously described methods (van der Laan and Thole, 1991). Spectra for standards of goethite, ferrihydrite, and magnetite were also collected alongside the experimental samples (Cutting et al., 2009).

\section{Batch Cr(VI) Removal Experiments}

Chromium(VI) reduction was determined by diphenyl carbazide (DPC) assay (Skougstad et al., 1979) against a standard calibration curve for known $\mathrm{Cr}(\mathrm{VI})$ concentrations using a Jenway $6715 \mathrm{UV} / \mathrm{Vis}$ spectrophotometer. Reaction vessels were $10 \mathrm{ml}$ glass vials with a headspace of $\mathrm{N} 2$ and the experiments were conducted in triplicates unless otherwise stated. The bio-reduced $\mathrm{Fe}(\mathrm{II})$-bearing samples were suspended in a buffer solution of $\mathrm{NaHCO}_{3}(80 \mathrm{mg} / \mathrm{l}), \mathrm{CaSO}_{4} \bullet 2 \mathrm{H}_{2} \mathrm{O}(30 \mathrm{mg} / \mathrm{l}), \mathrm{MgSO}_{4}(30 \mathrm{mg} / \mathrm{l})$, and $\mathrm{KCl}(2 \mathrm{mg} / \mathrm{l})$ that was purged with $\mathrm{N}_{2}: \mathrm{CO}_{2}(80: 20)$. The final concentration of the $\mathrm{Fe}(\mathrm{III})$ sources were $1,1.5 \mathrm{~g} / \mathrm{l}$ total $\mathrm{Fe}$ for ZH2015, ZH2016 samples, and 0.3, $0.55 \mathrm{~g} / \mathrm{l} \mathrm{Fe}$ for LPTH, respectively. To account for $\mathrm{Cr}(\mathrm{VI})$ removal by sorption, nonreduced slurry samples were used as a control. A solution of $\mathrm{K}_{2} \mathrm{CrO}_{4}(25 \mathrm{mM})$ was prepared in $18.2 \mathrm{M} \Omega$ water and purged with $\mathrm{N}_{2}$ gas. This was added to the reaction vessel, $10 \mathrm{ml}$ glass vials with slurries to a final concentration of $0.7 \mathrm{mM} \mathrm{Cr}(\mathrm{VI})$ and incubated on a roller shaker under dark conditions. The samples were collected at defined intervals from the start of the experiment (T0) up to $6 \mathrm{~h}$, with an additional final reading at $12 \mathrm{~h}$. These were collected by using an $\mathrm{N}_{2}$-purged syringe and passed through a filter with a $0.22 \mu \mathrm{m}$ cut-off. The reaction rates ( $k$ obs) were calculated using pseudo-first-order kinetics by the following rate equation:

$$
d \frac{[C r(V I)]}{d t}=-k o b s[C r(V I)]
$$

Different concentrations of slurries (equivalent iron) were used, and rates of reduction were normalized to the iron loading.

\section{Life Cycle Assessment (LCA) and Life Cycle Costing (LCC)}

LCA and LCC (according to the ISO standards: 14040, 14041, and 14044) can be carried out in four phases: (i) goal and scope definition; (ii) inventory analysis; (iii) impact assessment; 
and (iv) interpretation (ISO 14040, 2006a; ISO 14041, 2006b; ISO 14044,2006 c), and were followed in this study. The goal of LCA employed here was to estimate environmental savings delivered through the biosynthesis of bionanomagnetite from waste $\mathrm{Fe}$ (III) sources, compared to more conventional abiotic industrial routes. All the four stages of LCA as recommended by the ISO. CML, ReCiPe and GaBi 6 provide their life cycle impact assessment (LCIA) methodology, i.e., the impact categories, unit of reporting, such as MJ of primary fossil depletion potential, sulfur dioxide equivalent for acidification potential and, characterization factor of each pollutant in that unit as the intensity of environmental stress. The CML method has been developed by the Institute of Environmental Sciences; Leiden University, Netherlands (Ecology, 2016) while the ReCiPe and GaBi 6 LCIA methodologies are available with the software developed by Thinkstep.

The functional unit employed was one mass unit of bionanomineral product. The boundary of the systems comprised all stages of production of bionanomagnetite, from cradle-to-grave. The logistics and end-use phase of bionanomagnetite or the cradle-to-grave phase has not been considered for comparative analysis between the new and industrial production systems, as the environmental impacts from this phase are common in all systems. The inventory data source used was Ecoinvent 3.0. The LCA results were reported in important impact categories; global warming potential provided by the CML method (Ecology, 2016); water depletion potential by the ReCiPe method and natural gas and abiotic fossil depletion potentials by $\mathrm{GaBi} 6.0$.

Similar to the LCA, the LCC analysis was applied to estimate the economic savings by the biosynthetic route compared to the industrial system, using the same system boundaries, and functional unit, as in the LCA. The operating costs due to raw material, heat and electricity consumptions across the life cycle stages were considered. Capital costs may be significant for the industrial system compared to the bioconversion of waste Fe(III) minerals. Capital costs available for the industrial system are indicative and do not correlate with the capacity or size of the system. For these reasons, only the operating cost savings by the new system are shown. Detailed capital and operating cost correlations and LCC evaluations are available (Sadhukhan et al., 2014).

\section{RESULTS}

\section{Physical Characterization of Fe(III) Substrates}

$\mathrm{XRD}$ analysis of sediment collected from the acid mine drainage site (ZH samples) as shown in Figure 1, identified mixtures of crystalline goethite and 2-line ferrihydrite with some detrital phases such as quartz and phyllosilicates. Interestingly, the sediment collected in 2015 (ZH2015) contained goethite with a lower crystallinity (i.e., with broader diffraction peaks), and a higher proportion of 2-line ferrihydrite than the fresh sediment from 2016 (ZH2016). XRD data for the Leptothrix sp. stabilized sheath derived samples (LEPTH) did not reveal a well-crystalline phase, in addition to quartz which was present as a detritic

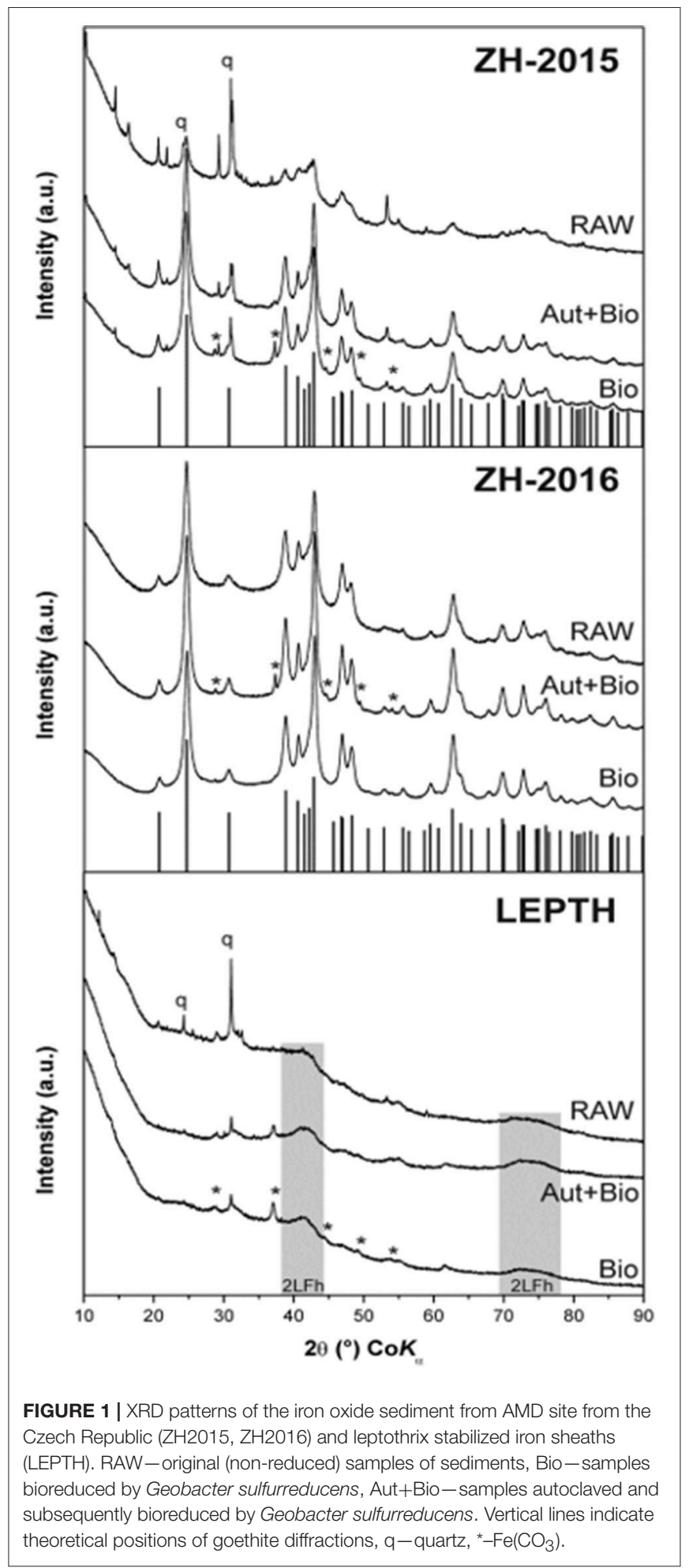

part of the sediment. The presence of amorphous iron oxide, represented by two broad humps at ca. 40 and $75^{\circ} 2$ Theta, typical for 2-line ferrihydrite, was also apparent in Figure 1. Mössbauer spectroscopy of the iron minerals in the sediments revealed the exclusive presence of ferric phases (i.e., with no indication of iron in the $2^{+}$oxidation state) before microbial reduction, 
indicated by a doublet in each of the spectra shown in Figure 2, most probably being in the nanocrystalline or superparamagnetic state (Machala et al., 2007; Safarik et al., 2015). Also, ZH2016 was the only sample that had a sextet component in the Mössbauer spectrum, and this is indicative of iron atoms in the form of magnetically-ordered goethite in Figure 2 (Sracek et al., 2014). The Mössbauer spectroscopy results are therefore in good agreement with the XRD data. Anionic analysis of the samples revealed a high concentration of carbonates in the starting material: $679 \mathrm{mg} / \mathrm{l}$ for LEPTH and approximately an average of $630 \mathrm{mg} / \mathrm{l}$ for $\mathrm{ZH}$ samples, which decreased marginally after washing (with deionized water) to 540 and $550 \mathrm{mg} / \mathrm{l}$, respectively.

\section{Microbial Reduction of Environmental Fe(III) Minerals}

Washed cell suspensions of G. sulfurreducens were added to slurries of the environmental Fe(III) minerals described above, with an appropriate electron donor (acetate) to determine if they could be transformed to nano-scale biomagnetite, or another
Fe(II)-bearing biomineral phase. Synthetic ferrihydrite was used as a positive control. Ferrozine assays were used to monitor iron reduction [as $\mathrm{Fe}(\mathrm{II})$ accumulation; Figure $\mathbf{3 A}$ ], these values were further normalized to total bioavailable iron (Figure 3B). Ferrous concentrations almost doubled within $2 \mathrm{~h}$ of incubation (Figure 3B), with similar rates of reduction, noted in both the $\mathrm{ZH} 2016$ sediments and the ferrihydrite positive control, which were marginally higher than for the LEPTH samples. At the end of $20 \mathrm{~h}$, the $\mathrm{Fe}$ (II) concentrations were approximately $17 \mathrm{mM}$ in the case of the ferrihydrite, $16 \mathrm{mM}$ for $\mathrm{ZH} 2016$, and $10 \mathrm{mM}$ for the LEPTH samples. The normalized values [Fe(II)/total Fe] showed that the bioreduction ratios were in the following order; ZH2016 $>$ F $>$ LEPTH as shown in Figure 3B. Qualitative differences were observed in all treatments, notably, the difference in the color of the mineral slurries. Ferrihydrite and LEPTH transformed into black suspensions, whereas ZH2016 became brown most likely due to the presence of recalcitrant goethite, along with $\mathrm{Fe}(\mathrm{II})$ phase(s) (Figure 2). The images of the reaction vessels and aliquots drawn from these at different time points are shown (Figures $\mathbf{S} 1$ and $\mathbf{S} 2$ respectively).

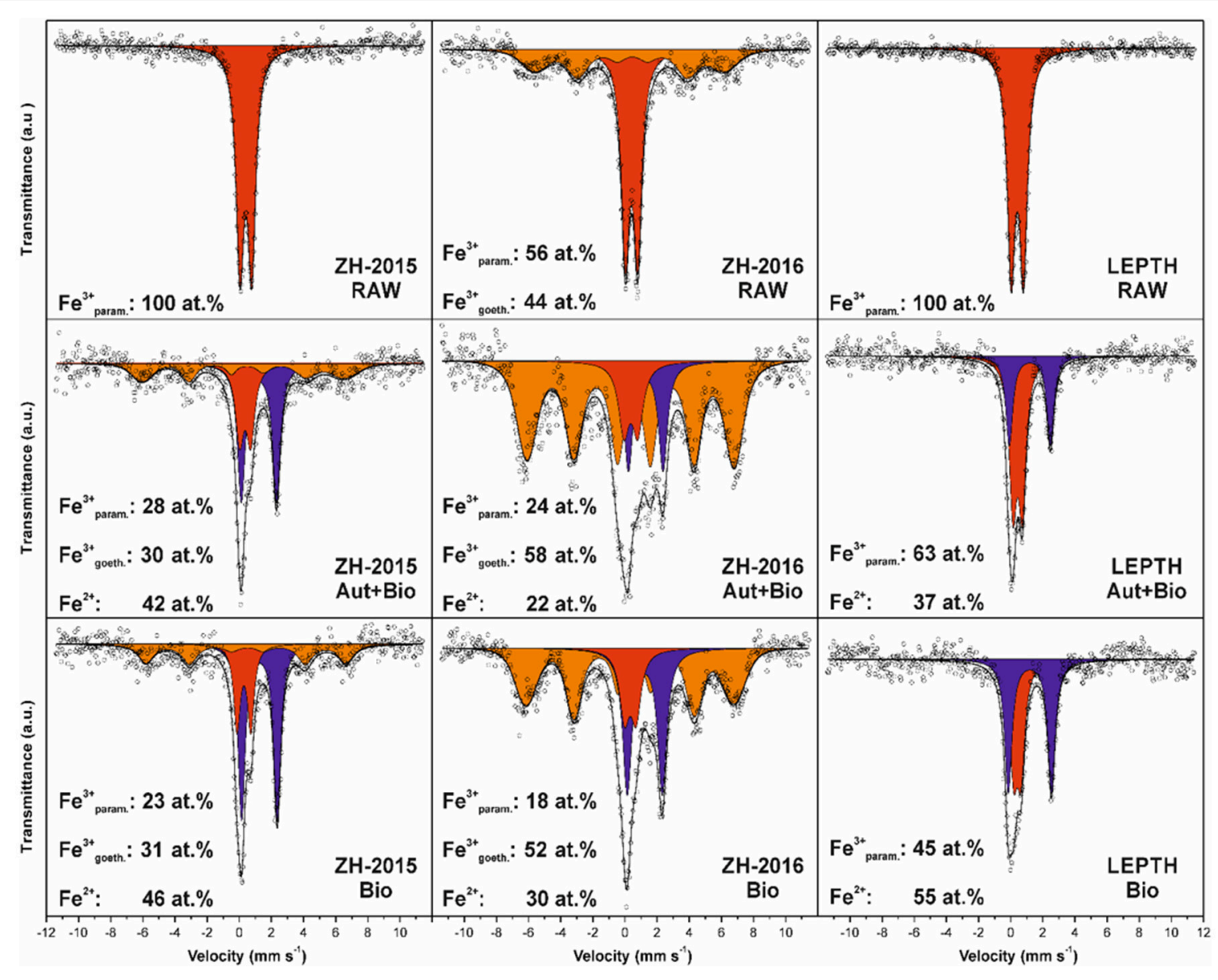

FIGURE 2 | Mössbauer spectroscopy data for the sediments without bioreduction (RAW) and treated samples: samples autoclaved before addition of Geobacter sulfurreducens are labeled as Autoclaved+Bioreduced (Aut+Bio) and samples with resting cells added without prior sterilization are labeled as Bioreduced (Bio). The individual spectral components are designated by color: red-Fe(III) in paramagnetic/superparamagnetic state, orange-Fe(III) in magnetically ordered state, blue-Fe(II). 

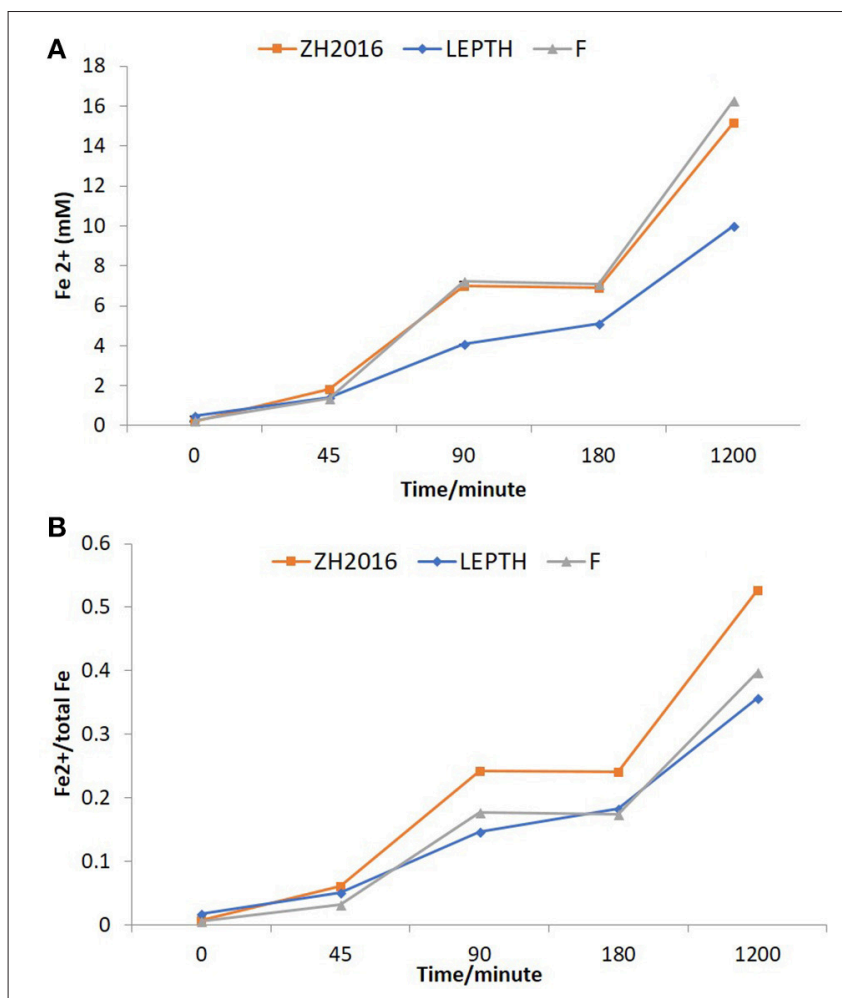

FIGURE 3 | (A) Fe ${ }^{2+}$ concentrations in batch reactors (mM). LEPTH (leptothrix stabilized sheaths), ZH2015 (sediment from AMD site), and F (laboratory synthesized 2-line ferrihydrite used as positive control). All samples are autoclaved before use. (B) $\mathrm{Fe}^{2+}$ normalized to the total bioavailable iron $(\mathrm{Fe})$ in the slurry in each reaction vessel. The $\mathrm{x}$-axis in each graph represents time in minutes.

To investigate the potential impact of high temperature on the stability of the starting mineral phases and the quality of bioreduced products, a separate experiment was conducted with autoclaved samples, before addition of the washed "resting" cell suspensions. The $\mathrm{Fe}(\mathrm{II})$ levels were measured at the start of the experiment, and after $16 \mathrm{~h}$ of incubation. Fe(II) accumulated in all the samples irrespective of the treatments, however, the nonautoclaved samples showed a greater extent of reduction [evident by elevated levels of $\mathrm{Fe}$ (II) in all the slurries in the following order ZH2016>LEPTH > ZH2015 as shown in Figure 4].

Mössbauer spectroscopic analyses show that ferrous iron atoms increased from 0 to 42 and $46 \%$ in autoclaved-bioreduced and non-autoclaved-bioreduced ZH2015 samples, respectively (based on relative spectral areas of all components in spectra of particular samples; Figure 2). A similar trend was observed for $\mathrm{ZH} 2016$ for autoclaved-bioreduced $\left(22 \%\right.$ of $\left.\mathrm{Fe}^{2+}\right)$ and nonautoclaved-bioreduced $\left(30 \%\right.$ of $\left.\mathrm{Fe}^{2+}\right)$ samples, but with a lower total extent of $\mathrm{Fe}(\mathrm{III})$ reduction. LEPTH samples followed the same trend and gave results of between 37 and $55 \%$ of $\mathrm{Fe}^{2+}$ in autoclaved-bioreduced and non-autoclaved-bioreduced samples, respectively.

From a mineralogical structure point of view, recrystallization occurred during the process of bioreduction (as evident from $\mathrm{XRD}$ and Mössbauer spectroscopy; as shown in Figures 1,

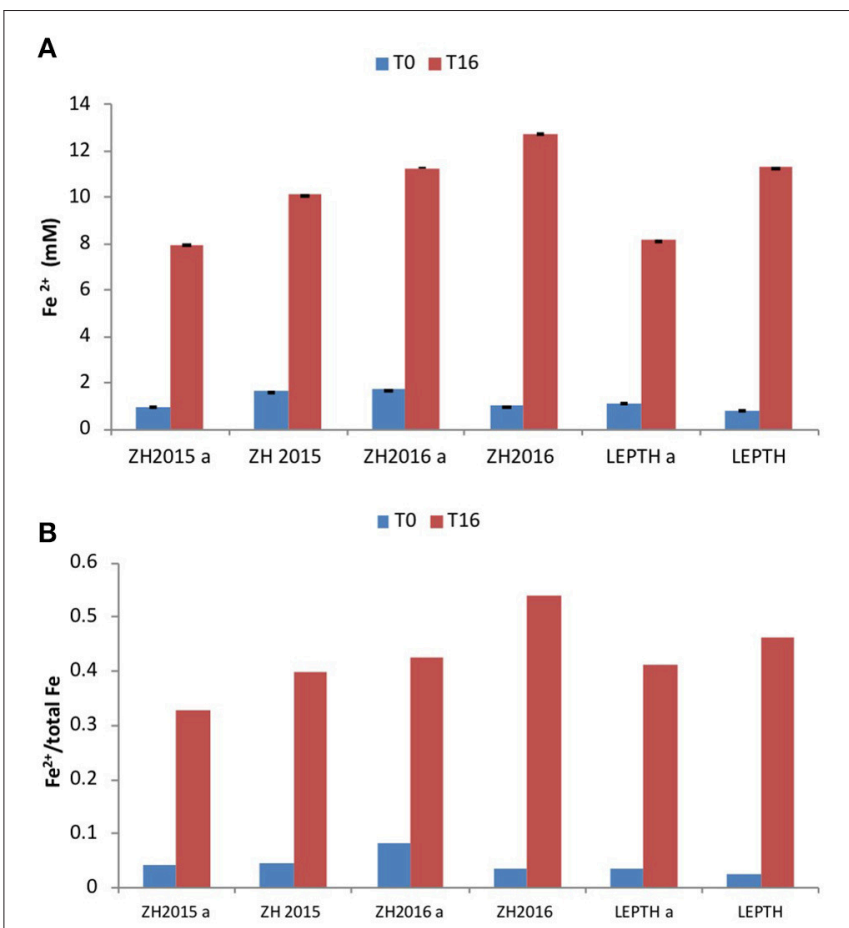

FIGURE 4 | (A) Fe $\mathrm{Fe}^{2+}$ levels (mmol/l) during bioreduction in reaction vessels with slurries ZH2015, ZH2016 A, and LEPTH (non -autoclaved and corresponding controls that have been autoclaved and denoted by letter " $A$ " before addition of resting cells. (B) Ratio of $\mathrm{Fe}^{2+}$ to total $\mathrm{Fe}$ in vials.

2). For both $\mathrm{ZH} 2015$ and $\mathrm{ZH} 2016$, partial recrystallization to magnetically ordered goethite was observed (Figure 2), where higher proportions of the sextet component in the spectra were found in the samples from autoclaved-bioreduction and nonautoclaved-bioreduction. There was a higher proportion of the goethite sextet in the ZH2016 samples (Figure 2), and this is consistent with the observed evolution of goethite crystallinity based on XRD (Figure 1). Also, in the case of the LEPTH sample, there was an apparent evolution of ferrihydrite crystallinity, where the broad diffraction "humps" in XRD patterns became slightly narrower for both the autoclaved and non-autoclaved bioreduced samples (Figure 1). Diffraction peaks at positions typical for siderite $\left(\mathrm{FeCO}_{3}\right)$ were also observed in XRD patterns of the bioreduced samples (both autoclaved and non-autoclaved; Figure 2). The highest proportion of such newly-formed ferrous carbonate was observed in the ZH2016 sample (both autoclaved and bioreduced) and amounted to $10 \mathrm{wt} . \%$.

X-ray absorption spectra (XAS; Figure 5) from the samples, were compared with spectra for standard goethite, ferrihydrite, and magnetite to help further characterize the starting material and bioreduced endpoints. The spectra for ZH2015, both before and after bioreduction was found to be similar to ferrihydrite, whereas the spectra for the ZH2016 sample was more similar to goethite in both the conditions. However, the difference between these two standard spectra is only discernible from the trough between the two peaks of the L3 edge, indicated by an arrow in Figure 5A. Sample analysis of the spectra from the LEPTH 

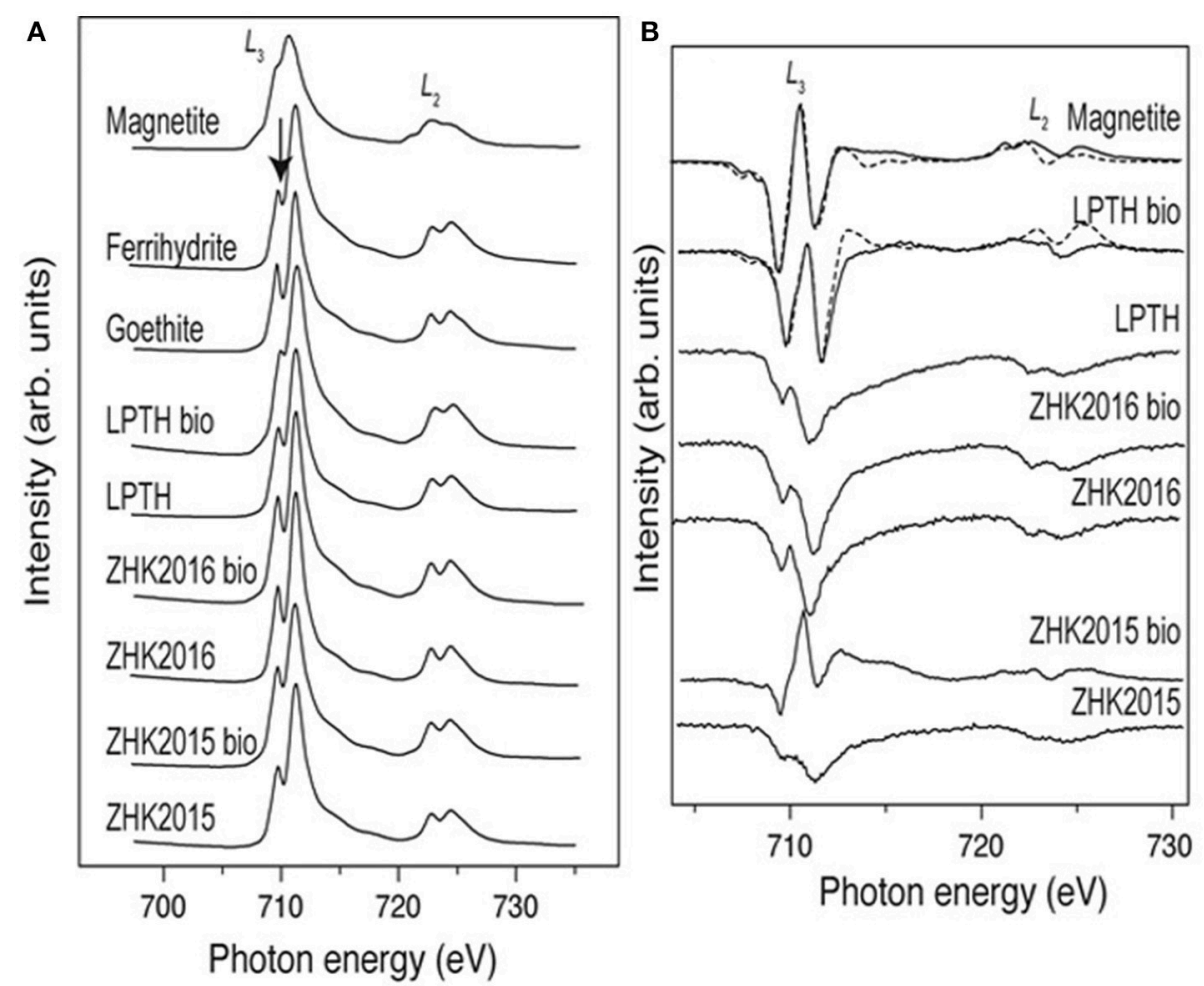

FIGURE 5 | (A) Fe $L_{2,3}$-edge XAS spectra for iron mineral phases goethite ferrihydrite, magnetite compared with sediments both bioreduced and non-reduced conditions, arrow identifies the trough between the peaks of the $L_{3}$ edge (left panel). (B) Shows the XMCD spectra for the sediments under similar conditions.

material (both before and after bioreduction), when compared to the standards, indicates that ferrihydrite was present before and after microbial reduction. The trough between the two peaks of the L3 edge is significantly diminished after bioreduction, suggesting a mixture of $\mathrm{Fe}(\mathrm{III})$-bearing material and a $\mathrm{Fe}(\mathrm{II})$ bearing phase, potentially magnetite. X-ray magnetic circular dichroism (XMCD) spectra shown in Figure 5B were derived from the XAS spectra in Figure 5A and represent magnetic components of the sample. The bioreduced ZH2016 sample did not show any magnetic characteristics. However, the spectra from the bioreduced ZH2015 sample suggests that a small amount of magnetic material was present, but this was dwarfed by the signal from the non-magnetic phases and therefore could not be fitted accurately. In contrast, spectra from the bioreduced LEPTH sample clearly contained the two negative peaks and one positive peak in the L3 edge of the spectrum that is indicative of the presence of magnetite and can be seen from a comparison with the standard magnetite sample in Figure 5B. Although the data are quite noisy, a tentative fit gives a $\mathrm{Fe}(\mathrm{II})$ : $\mathrm{Fe}(\mathrm{III})$ ratio of 1:2.3, which compares to stoichiometric magnetite, which would have a ratio of 1:2. Therefore, both XAS and XMCD data show a definitive sink of Fe(II) present within the sample, with the presence of magnetite indicated in the bioreduced LEPTH sample.

TEM analysis of the bioreduced slurries showed the presence of nanoparticles with marked aggregation and sizes ranging from 100 to $300 \mathrm{~nm}$ diameter in samples from both of the sites (Figures 6A and $6 \mathrm{C}$ respectively). The electron diffraction patterns showed that the ZH2015 sample was crystalline (Figure 6B) whereas the LEPTH was amorphous or nanocrystalline (Figure 6D). The EDX spectra for both samples (Figure S3) was consistent with an iron-rich composition together with the presence of other elements as sodium, calcium, and aluminum as expected in natural samples.

\section{Reactivity Tests With the Bioreduced Slurries Using $\mathrm{Cr}(\mathrm{VI})$ as a Model Contaminant}

The reactivity of the bioreduced slurries was measured by their ability to remove $\mathrm{Cr}(\mathrm{VI})$ [via $\mathrm{Fe}(\mathrm{II})$-mediated reduction]. Two experiments were undertaken using post-reduction minerals at Fe loadings of 1 or $1.5 \mathrm{~g} / \mathrm{l}$ and a starting concentration of $\mathrm{Cr}(\mathrm{VI})$ of $0.7 \mathrm{mM}$ (Figures 7, 8). Bionanomagnetite (BNM) synthesized from ferrihydrite was used as a positive control as it has been shown to remove $\mathrm{Cr}$ (VI) efficiently (Watts et al., 2014, 2015; Joshi et al., 2018).

Figure 7A shows $\mathrm{Cr}(\mathrm{VI})$ concentration at different time points when reacted with bioreduced ZH2015, ZH2016, and $\mathrm{BNM}$ at an equivalent concentration ( $\mathrm{Fe}$ at $1 \mathrm{~g} / \mathrm{l})$. Figure $7 \mathrm{~B}$ shows a comparison of reactivity of ZH2015 and BNM at 1 and $1.5 \mathrm{~g} / \mathrm{l}$. At $1 \mathrm{~g} / \mathrm{l} \mathrm{Fe}$ both BNM and bioreduced slurries removed approximately $62 \% \mathrm{Cr}(\mathrm{VI})$. The $\mathrm{Cr}(\mathrm{VI})$ removal increased to $85 \%$ at higher Fe loading (Figure 7B). The native, non-bioreduced 

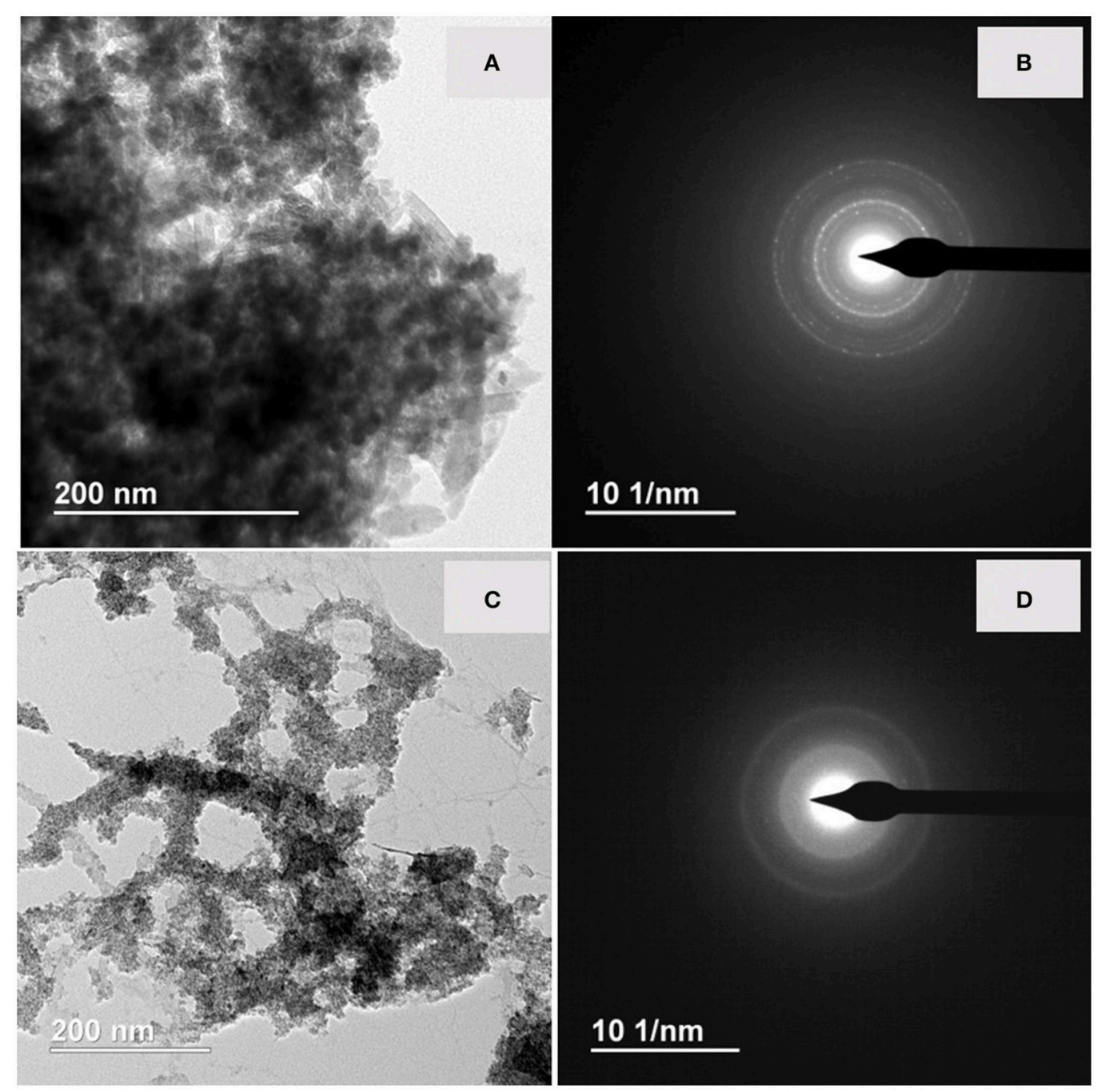

FIGURE 6 | (A) TEM micrograph of bioreduced ZH2015 sediment, (B) EDX spectrum of the nanoparticle, (C) TEM image for bioreduced LEPTH and corresponding EDX spectrum of (D).

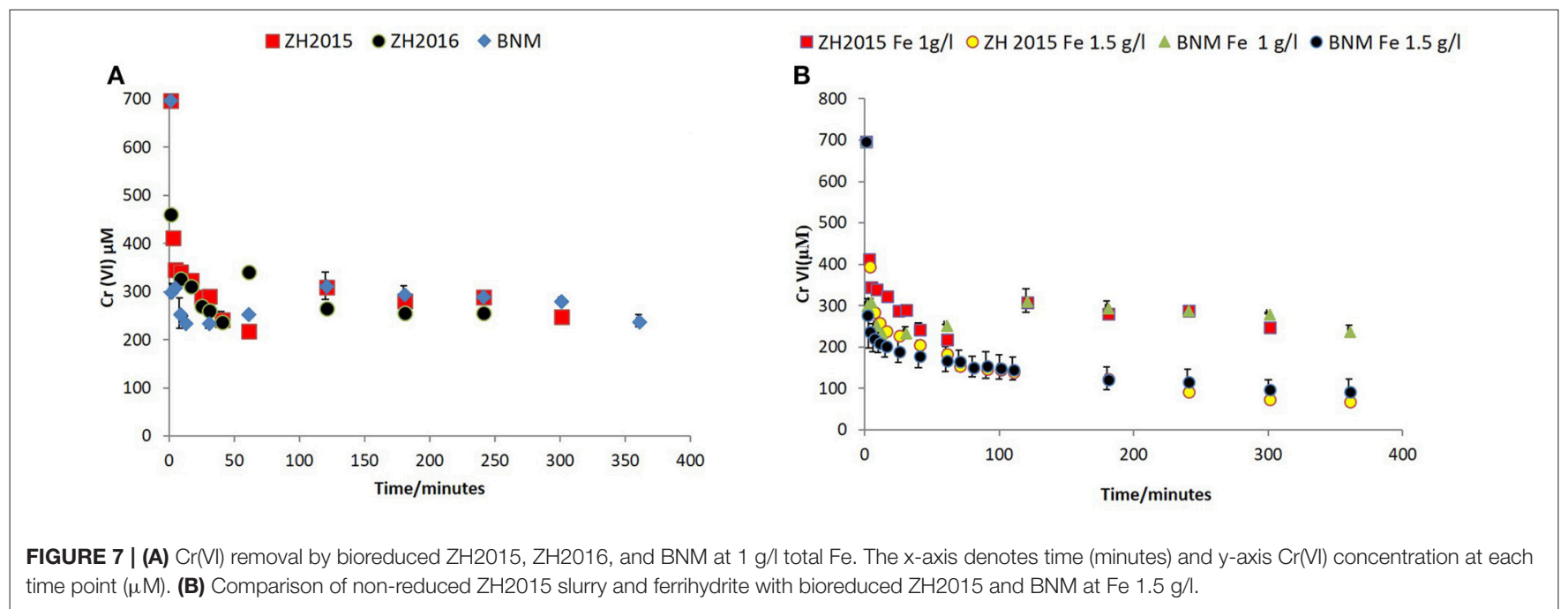


sample slurries and ferrihydrite, were also tested as controls (at $1.5 \mathrm{~g} / \mathrm{l} \mathrm{Fe}$ ), for surface sorption and were found to remove only approximately $20 \%$ of $\mathrm{Cr}(\mathrm{VI})$ (Figure 8A). In the case of the bioreduced LEPTH samples, Cr(VI) removal could not be carried out at a similar concentration of total Fe, as the reaction progressed too rapidly to quantify. Therefore, $1 \mathrm{mM}$ $\mathrm{Cr}(\mathrm{VI})$ was tested against two concentrations of the bioreduced LEPTH samples; 0.3 and $0.55 \mathrm{~g} / \mathrm{l}$ total $\mathrm{Fe}$, respectively as shown in Figure 8B. Higher $\mathrm{Cr}(\mathrm{VI})$ removal was seen with an increase in iron content in the slurries, which was evident within the first hour of incubation (50\% removal at Fe $0.3 \mathrm{~g} / \mathrm{l}$ and $70 \%$ at $0.5 \mathrm{~g} / \mathrm{l} \mathrm{Fe}$ ). The reaction rates were determined as described previously and the results shown in Table $\mathbf{S} 1$ in the Supplementary Information.

\section{LCA Analysis}

$1 \mathrm{~kg}$ of BNM synthesis using a current industrial system (comprising mining, crushing and grinding, concentration, filtration, and pelletisation), consumes $1.26 \mathrm{~kg}$ iron sulfate, $0.36 \mathrm{~kg}$ sodium hydroxide in $50 \%$ water, $1.4 \mathrm{MJ}$ natural gas for heat and $0.3 \mathrm{MJ}$ medium voltage electricity, respectively (Shemfe et al., 2018). Using these consumptions and analyzing life cycle inventories from the Ecoinvent 3.0 database and life cycle impacts of the current industrial system, savings (in global warming potential, natural gas, fossil resources and water), obtained by the proposed bioreduction synthesis approach are; $0.77 \mathrm{~kg} \mathrm{CO}_{2}$ eq., $3.53 \mathrm{MJ}, 13.73 \mathrm{MJ}$, and $4.97 \mathrm{~m}^{3}$, respectively, per $\mathrm{kg}$ of BNM synthesis. The environmental impact hotspots are raw material resourcing, followed by natural gas and electricity consumptions and, avoiding these means savings in environmental impacts. Applying the prices of iron sulfate, sodium hydroxide, natural gas, and electricity at competitive global rates, EUR 228 per kg, EUR 78 per kg, EUR 0.05 per MJ, and EUR 0.08 per MJ, respectively, an initial estimate of operating cost savings obtained is EUR 315 per $\mathrm{kg}$ BNM synthesized. The LCC hotspots in the descending order are $\mathrm{Fe}(\mathrm{III})$ source and other raw materials, natural gas, and electricity, respectively. These costs could be potentially removed by the proposed bioreduction approach. Furthermore, economic savings by the proposed biosynthesis compared to current industrial practices are expected to be even higher, if capital and fixed operating costs are taken into account.

\section{DISCUSSION}

We have shown that microbes can reduce natural Fe(III) minerals to make Fe(II)-bearing nanoparticles. The XRD and Mössbauer spectroscopy analysis of the raw sediments from Zlate Hory showed a mixture of 2-line ferrihydrite and goethite. Similarly, the Leptothrix sp. stabilized material was an amorphous Fe(III) oxide. The bioreduction process produced Fe(II) mineral bearing phases from these starting materials, with some peaks similar to magnetite (others identical to magnetically ordered goethite).

The Fe(II)-bearing mineral phases synthesized from these sediments removed $\mathrm{Cr}(\mathrm{VI})$ in batch reactor studies with some similarities (reactivity) to fine grain biogenic magnetite. This suggests that these bioreduced sediments are amenable to treatment of priority radionuclides [e.g., Tc(VII)], heavy metals [e.g., $\mathrm{Cr}(\mathrm{VI})$ ], as tested here and $\mathrm{Hg}$ (II) (Wiatrowski et al., 2009), metalloids [As(V), and Se(IV)] (Scheinost and Charlet, 2008) and organics (TCE/PCE; Watts et al., 2015, 2016).

The Fe(II) nanomaterials synthesized could be used for insitu treatment of sediments, e.g., by adding an organic coating to facilitate transport to hotspots of contamination (Joshi et al., 2018) or used uncoated for use in a reactive permeable barrier for the treatment of a migrating plume. They would also be useful for treating contaminated waters containing metals and organics, and the magnetic properties of at least one of the materials (biomagnetite from the LEPTH substrate) would facilitate metal recovery from treated waters, allowing for the recovery of valuable metals from wastewater streams (e.g., for silver, gold, and copper).

The endpoints of bioreduction of the materials were all Fe(II)-bearing but showed some differences (seen by Mössbauer spectroscopy, XAS and XMCD, and geochemical assays). The
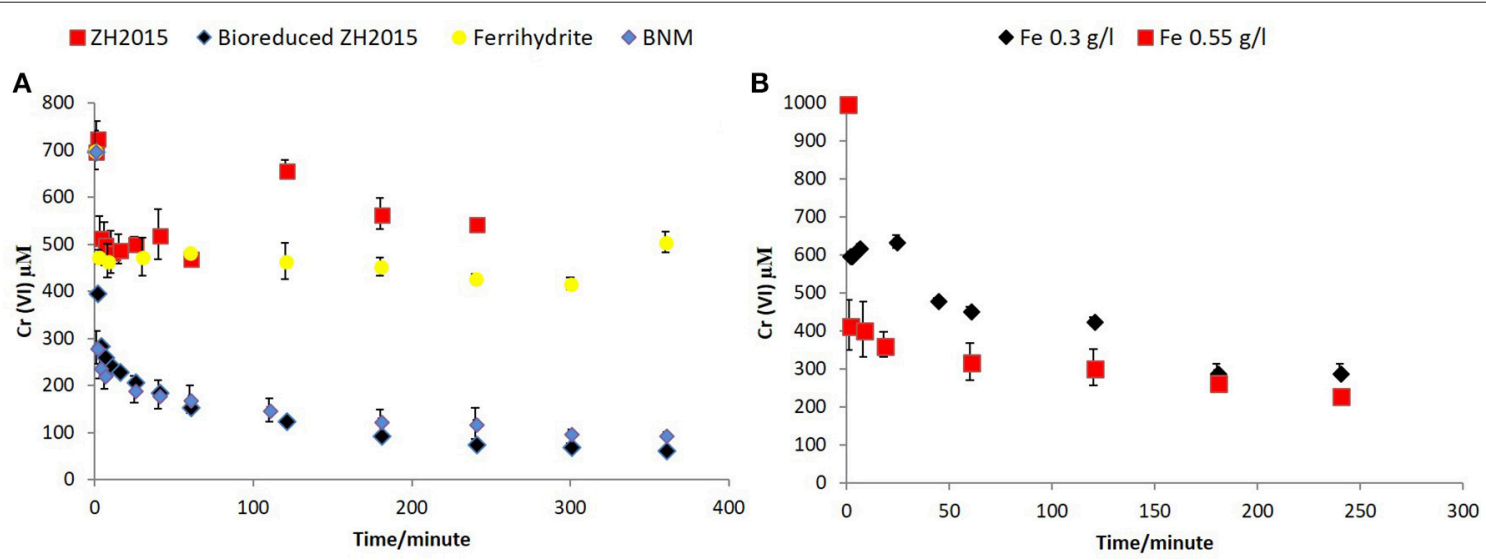

FIGURE 8 | (A) Cr (VI) removal comparison of non-reduced and bioreduced ZH2015 to Ferrihydrite and biomagnetite at a total iron loading $1.5 \mathrm{~g} / \mathrm{l}$ (B) Cr(VI) removal by bioreduced LEPTH at 0.3 and $0.55 \mathrm{~g} / \mathrm{l}$ total Fe. 
latter (ferrozine) assays, do not always give a true reflection of the amount of $\mathrm{Fe}$ (III) in a material. These discrepancies could be partially explained due to possible abiotic transformations (during storage of the slurries), or more likely an underestimate of $\mathrm{Fe}(\mathrm{II})$ levels measured, due to incomplete extraction of structurally incorporated $\mathrm{Fe}(\mathrm{II})$ using weak acid $(0.5 \mathrm{M} \mathrm{HCl})$ used in the standard ferrozine assays. The presence of siderite can be explained by the presence of high levels of carbonates in the sediment from the start.

Collectively this study shows that a range of Fe(II)-containing biomaterials, including a very fine grain nanomagnetite, can be produced from abundant natural Fe(III) substrates. These bionanominerals can be used for a variety of applications (e.g., catalysis, remediation) and, applications where the magnetic properties are crucial (Byrne et al., 2013). It is feasible that the magnetic properties could be enhanced by the inclusion of dopants in the substrates (either naturally occurring or added) such as Co or Zn (Byrne et al., 2013).

Finally, LCA and LCC analyses are crucial to driving the adoption of these processes by industry, and clearly, show the bottlenecks and cost prohibitive steps in the production of functional Fe(II)-bearing bionanomaterials. By comparison with the conventional "abiotic" production of magnetic Fe particles, our work shows that the bioconversion of natural Fe(III) minerals offers a far more sustainable (and potentially more cost-effective) route to the production of functional Fe(II) nanominerals. This concept could be expanded by tapping into a potential plentiful supply of waste $\mathrm{Fe}(\mathrm{III})$ materials from industry, including those available from the metal, mining, wastewater, and pigment industries.

\section{AUTHOR CONTRIBUTIONS}

NJ performed the experiments described in the manuscript. JF provided samples of the iron oxyhydroxide precipitates,

\section{REFERENCES}

Arenholz, E., and Prestemon, S. (2005). Design and performance of an eight-pole resistive magnet for soft $\mathrm{x}$-ray magnetic dichroism measurements. Rev. Sci. Instrum. 76:083908. doi: 10.1063/1.2008027

Byrne, J. M., Coker, V. S., Moise, S., Wincott, P. L., Vaughan, D. J., Tuna, F., et al. (2013). Controlled cobalt doping in biogenic magnetite nanoparticles. J. R. Soc. Interface 10:20130134. doi: 10.1098/rsif.2013.0134

Byrne, J. M., Telling, N. D., Coker, V. S., Pattrick, R., Van Der Laan, G., Arenholz, E., et al. (2011). Control of nanoparticle size, reactivity, and magnetic properties during the bio production of magnetite by Geobacter sulfurreducens. Nanotechnology 22:455209. doi: 10.1088/0957-4484/22/45/455709

Coker, V. S., Bennett, J. A., Telling, N. D., Henkel, T., Charnock, J. M., Van Der Laan, G., et al. (2010). Microbial engineering of nanoheterostructures: biological synthesis of a magnetically recoverable palladium nanocatalyst. ACS Nano. 4, 2577-2584. doi: 10.1021/nn9017944

Coker, V. S., Garrity, A., Wennekes, W. B., Roesink, H. D., Cutting, R. S., and Lloyd, J. R. (2014). Cr(VI) and azo dye removal using a hollow-fiber membrane system functionalized with a biogenic Pd-magnetite catalyst. Environ. Sci. Technol. 35, 1046-1054. doi: 10.1080/09593330.2013.859738 performed Mössbauer and XRD analysis and contributed to the corresponding details in the paper. VC analyzed the samples for $\mathrm{XAS}$, and XMCD wrote the corresponding method and result section. IS provided the LEPTH sediment. HB performed the imaging, TEM, and EDX. JS performed the life cycle assessments and life cycle costings. JL guided the experimental programme and worked with NJ on the preparation of the final draft of the manuscript.

\section{FUNDING}

This research work has been supported by funding from the European Union Seventh Framework Programme (FP7/2007-2013) under Grant Agreement No. 309517 (NANOREM). The authors further acknowledge the support by the Ministry of Education, Youth and Sports of the Czech Republic under Operational Program Research, Development and Education-European Regional Development Fund (project no. CZ.02.1.01/0.0/0.0/16_019/0000754) and the assistance provided by the Research Infrastructures NanoEnviCz under project LM2015073 and by the project New composite materials for environmental applications (CZ.02.1.01/0.0/0.0/17_048/0007399).

\section{ACKNOWLEDGMENTS}

The author would like to thank Dr. John Waters, Mr. Paul Lythgoe, and Mr. Alastair Bewsher for their assistance with XRD, ICP-AES, and IC analyses, respectively.

\section{SUPPLEMENTARY MATERIAL}

The Supplementary Material for this article can be found online at: https://www.frontiersin.org/articles/10.3389/fenvs. 2018.00127/full\#supplementary-material

Crean, D. E., Coker, V. S., van der Laan, G., and Lloyd, J. R. (2012). Engineering biogenic magnetite for sustained $\mathrm{Cr}(\mathrm{VI})$ remediation in flow-through systems. Environ. Sci. Technol. 46, 3352-3359. doi: 10.1021/es2037146

Cutting, R. S., Coker, V. S., Fellowes, J. W., Lloyd, J. R., and Vaughan, D. J. (2009). Mineralogical and morphological constraints on the reduction of Fe(III) minerals by Geobacter sulfurreducens. Geochim. Cosmochim. Acta 73, 4004-4022. doi: 10.1016/j.gca.2009.04.009

Cutting, R. S., Coker, V. S., Telling, N. D., Kimber, R. L., Lang,., G. V. D., Pattrick, R. A. D., et al. (2012). Microbial reduction of arsenic-doped schwertmannite by Geobacter sulfurreducens. Environ. Sci. Technol. 46, 12591-12599. doi: 10.1021/es204596z

Cutting, R. S., Coker, V. S., Telling, N. D., Kimber, R. L., Pearce, C. I., Ellis, B. L., et al. (2010). Optimizing $\mathrm{Cr}(\mathrm{VI})$ and $\mathrm{Tc}(\mathrm{VII})$ remediation through nanoscale biomineral engineering. Environ. Sci. Technol. 44, 2577-2584. doi: 10.1021/es902119u

Ecology C.-D.O.I (2016). Avaialble online at: http://www.cml.leiden.edu/software/ data-cmlia.htmlgetting-and-using-the-database

Filip, J., Karlicky, F., Marusak, Z., Lazar, P., Cernik, M., Otyepka, M., et al. (2014). Anaerobic reaction of nanoscale zerovalent iron with water:mechanism and kinetics.J. Phys. Chem. C 118,13817-13825. doi: 10.1021/jp501846f 
Filip, J., Zboril, R., Schneeweiss, O., Zeman, J., Cernik, M., Kvapil, P., et al. (2007). Environmental applications of chemically pure natural ferrihydrite. Environ. Sci. Technol. 41, 4367-4374. doi: 10.1021/es062312t

Ingale, A. G., and Chaudhari, A. N. (2013). Biogenic synthesis of nanoparticles and potential applications: an eco- friendly approach. J. Nanomed. Nanotechol. 4:165. doi: 10.4172/2157-7439.1000165

ISO 14040 (2006a). Environmental Management - Life Cycle Assessment - Principles and Framework. International Organization for Standardization.

ISO 14041 (2006b). Environmental Management - Life Cycle Assessment - Goal and Scope Definition - Inventory Analysis. International Organization for Standardization.

ISO 14044 (2006c). Environmental Management - Life Cycle Assessment Requirements and Guidelines. International Organization for Standardization.

Joshi, N., Liu, F., Watts, M. P., Williams, H., Coker, V. S., Schmid, D., et al. (2018). Optimising the transport properties and reactivity of microbially-synthesised magnetite for in situ remediation. Sci. Rep. 8:4246. doi: 10.1038/s41598-018-21733-y

Laurent, S., Forge, D., Port, M., Roch, A., Robic, C., Elst, L. V., et al. (2008). Magnetic iron oxide nanoparticles: synthesis, stabilization, vectorization, physicochemical characterizations, and biological applications. Chem. Rev. 108, 2064-2110. doi: 10.1021/cr068445e

Lloyd, J. R. (2003). Microbial reduction of metals and radionuclides. FEMS Microbiol. Rev. 27, 411-425. doi: 10.1016/S0168-6445(03)00044-5

Lloyd, J. R., Byrne, J. M., and Coker, V. S. (2011). Biotechnological synthesis of functional nanomaterials. Curr. Opin. Biotechnol. 22, 509-515. doi: 10.1016/j.copbio.2011.06.008

Lovley, D. R., and Phillips, E. J. P. (1986). Availability of ferric iron for microbial reduction in bottom sediments of the freshwater tidal potomac river. Appl. Environ. Microbiol. 52, 751-757.

Lovley, D. R., Stolz, J. F., Nord, G. L., and Phillips, E. J. (1987). Anaerobic production of magnetite by a dissimilatory iron-reducing microorganism. Nature 330, 252-254. doi: 10.1038/330252a0

Macaskie, L. I. P., Mikheenko, P., Yong, Deplanche, K., Murray, A. J., Paterson-Beedle, M., et al. (2010). Today's wastes, tomorrow's materials for environmental protection. Hydrometallurgy 104, 483-487. doi: 10.1016/j.hydromet.2010.01.018

Machala, L., Zboril, R., Sharma, V. K., Filip, J., Schneeweiss, O., and Homonnay, Z., (2007). Mössbauer characterization and in Situ monitoring of thermal decomposition of potassium ferrate(VI), K 2 FeO4 in static air conditions. J. Phys. Chem. B. 111:4280-4286. doi: 10.1021/jp068272x

Majiewsky, P., and Thierry, B. (2007). Functionalized magnetite nanoparticlessynthesis, properties, and bio-applications. Crit. Rev. Solid State Mater. Sci. 32, 203-215. doi: 10.1080/10408430701776680

Mandal, D., Bolander, M. E., Mukhopadhyay, D., Sarkar, G., and Mukherjee, P. (2006). The use of microorganisms for the formation of metal nanoparticles and their application. Appl. Microbiol. Biotechnol. 69, 485-592. doi: 10.1007/s00253-005-0179-3

Pattrick, R. A. D., Van Der Laan, G., Henderson, C. Michael B., Kuiper, P., Dudzik, E., et al (2002). Cation site occupancy in spinel ferrites studied by Xray magnetic circular dichroism: developing a method for mineralogists. Er. J. Mineral. 14, 1095-1102. doi: 10.1127/0935-1221/2002/0014-1095

Sadhukhan, J., Joshi, N., Shemfe, B., and Lloyd, J. R. (2017). Life cycle assessment of sustainable raw material acquisition for functional magnetite bionanoparticle production. J. Environ. Manage. 199, 116-125. doi: 10.1016/j.jenvman.2017.05.048

Sadhukhan, J., Ng, K. S., and Hernandez, E. M. (2014). Biorefineries and Chemical Processes: Design, Integration and Sustainability Analysis. John Wiley \& Sons, Ltd.

Safarik, I., Angelova, R., Baldikova, E., Pospiskova, K., and Safarikova, M. (2017). Leptothrix sp. sheaths modified with iron oxide particles: magnetically responsive, high aspect ratio functional materia. Mater. Sci. Eng. C. 71, 1342-1346. doi: 10.1016/j.msec.2016.10.056

Safarik, I., Filip, J., Horska, K., Nowakova, M., Tucek, J., Safarikova, M., et al. (2015). Magnetically-modified natural biogenic iron oxides for organic xenobiotics removal. Int. J. Environ. Sci. Technol. 12, 673-682. doi: $10.1007 /$ s13762-013-0455-1

Scheinost, A. C., and Charlet, L. (2008). Selenite reduction by mackinawite, magnetite and siderite: XAS characterization of nanosized redox products. Environ. Sci Technol. 15, 1984-1989. doi: 10.1021/es071573f

Shemfe, M., Gadkari, S., Yu, E., Rasul, S., Scott, K., Head, I., et al. (2018). Life cycle, techno-economic and dynamic simulation assessment of bioelectrochemical systems: a case of formic acid synthesis. J. Biores. Technol. 255, 39-49. doi: 10.1016/j.biortech.2018.01.071

Skougstad, M. W. F., Friedman, L. C., Erdman, D. E., and Duncan, S. S. (1979). Method for Determination of Inorganic Substances in Water and Fluvial Sediments. Geological Survey (US), 545.

Sracek, O., Mihaljevič, M., Kríbek, B., Majer, V., Filip, J., Vaněk, A., et al. (2014). Geochemistry and mineralogy of vanadium in mine tailings at Berg Aukas, northeastern Namibia. J. African Earth Sci. 96, 180-189. doi: $10.1016 /$ j.jafrearsci.2014.04.003

Stookey, L. L. (1970). Ferrozine-a new spectrophotometric reagent for iron. Anal. Chem. 42, 779-781. doi: 10.1021/ac60289a016

Telling, N., Coker, V., Cutting, R., LanVander, G., Pierce, C., Pattrick, R. A. D., et al. (2009). Remediation of $\mathrm{Cr}(\mathrm{VI})$ by biogenic magnetic nanoparticles: an X-ray magnetic circular dichroism study. Appl. Phys. Lett. 95:163701 doi: $10.1063 / 1.3249578$

van der Laan, G., and Thole, B. T. (1991). Strong magnetic x-ray dichroism in 2p absorption spectra of 3d transition-metal ions. Phys. Rev. B. 43, 13401-13411. doi: 10.1103/PhysRevB.43.13401

Watts, M., Cutting, R. S., Joshi, N., and Lloyd, J. (2016). Highly efficient degradation of organic pollutants using a microbially-synthesized nanocatalyst. Int. Biodeteriorat. Biodegrad. 119, 155-161. doi: 10.1016/j.ibiod.2016.12.008

Watts, M. P., Coker, V. S., Parry, S. A., Pattrick, R. A. D., Thomas, R. A. P., Kalin, R., et al. (2014). Biogenic nano-magnetite and nano-zero valent iron treatment of alkaline $\mathrm{Cr}(\mathrm{VI})$ leachate and chromite ore processing residue. Appl. Geochem. 54, 27-42. doi: 10.1016/j.apgeochem.2014.12.001

Watts, M. P., Coker, V. S., Parry, S. A., Thomas, R. A. P., Kalin, R., and Lloyd, J. R. (2015). Effective treatment of alkaline $\mathrm{Cr}(\mathrm{VI})$ contaminated leachate using a novel Pd-bionanocatalyst; the impact of electron donor and aqueous geochemistry. Appl. Catal. B. Environ. 170-171, 162-172. doi: 10.1016/j.apcatb.2015.01.017

Wiatrowski,.H. A., Das, S., Kukkadapu, R. K., Ilton, E. S., Tamar, B., and Nathan, Y. (2009). Reduction of $\mathrm{Hg}(\mathrm{II})$ to $\mathrm{Hg}(0)$ by magnetite. Environ. Sci. Technol. 15, 5307-5313. doi: 10.1021/es9003608

Zak, T., and Jiraskova, Y. (2006). CONFIT: Mössbauer spectra fitting program. Surf. Interface Anal. 38, 710-714. doi: 10.1002/sia.2285

Zhang, W. X., and Elliot, D. W. (2006). Applications of iron nanoparticles for groundwater remediation. Remediation 16, 7-21. doi: 10.1002/rem.20078

Conflict of Interest Statement: The authors declare that the research was conducted in the absence of any commercial or financial relationships that could be construed as a potential conflict of interest.

Copyright (C) 2018 Joshi, Filip, Coker, Sadhukhan, Safarik, Bagshaw and Lloyd. This is an open-access article distributed under the terms of the Creative Commons Attribution License (CC BY). The use, distribution or reproduction in other forums is permitted, provided the original author(s) and the copyright owner(s) are credited and that the original publication in this journal is cited, in accordance with accepted academic practice. No use, distribution or reproduction is permitted which does not comply with these terms. 